Send your letters to the editor, British Dental Journal, 64 Wimpole Street, London W1G 8YS or by email tobdj@bda.org

Priority will be given to letters less than 500 words long. Letters should be typed. Authors must sign the letter, which may be edited for reasons of space

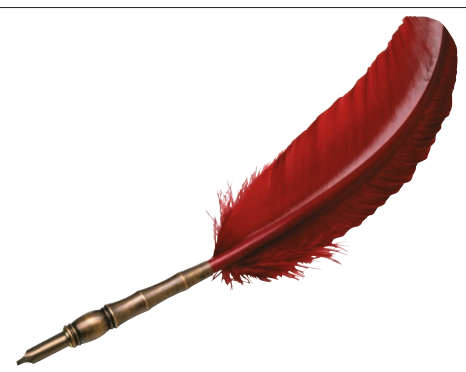

the findings from PDS pilots that have been running since 1998 and reinforced by the Modernisation Agency pilots which started in November 2003. The National Audit Office (NAO) welcomed these moves and voiced support for the modernisation programme (but did recognise that there are significant risks).

Your correspondent mentioned patient contribution to NHS funds and NAO report highlighted a total NHS spend on dentistry of $£ 2.3$ billion, incorporating hospital and community dental services as well as primary care provided by general dental and personal dental service practitioners. Hospital and community dental services are generally free to patients. Even within primary care dentistry, the contribution made by patients through dental charges represents less than $30 \%$ of the total cost of services. In 2003/4 in England, gross expenditure on the General Dental Service totalled nearly $£ 1.8$ billion, of which patient charge income contributed less than £0.5 billion. This is because many patients, such as children and adults on low incomes, pay no charges for their treatment, and dentists receive various payments and allowances in addition to their treatment fees, such as commitment payments and reimbursement of business rates, which attract no copayment from patients. Entitlement to help with the cost of dental treatment is based on the principle that those who can afford to contribute should do so, while those who are likely to have difficulty in paying should be protected.

I acknowledge that some patients have had difficulty accessing a dentist in some areas of the country. However, I can assure you that these issues are being addressed not least by the addition of the equivalent of 1,000 whole time dentists by October 2005 . This measure will enable up to an extra two million people to be treated. In the longer term, the planned 25\% increase in the number of undergraduate training places supported by capital investment in dental training establishments of up to £80m over four years - will make significant inroads in addressing the workforce problems we are currently encountering.

I agree that we need to utilise fully the skills of the wider dental team. The roles of dental therapists and hygienists are central to this changed agenda. We have expanded the total number of dental therapist training places from 50 to 200 and we have opened a new School for Professionals Complementary to Dentistry (PCDs) at Portsmouth University. The workforce of the future will undoubtedly be more of a team with much greater use of PCDs.

Turning to the point about registration, continuing professional development and training being mandatory: these are at the moment, but should become part of the contractual arrangements and participation should not result in financial loss to the practitioner. With regard to "luxury items", it is entirely appropriate that treatment that is clinically necessary should be available on the NHS. I am confident that the new arrangements will ensure that dentistry becomes fully integrated within the NHS family and, most importantly, responsive to the needs of the local population.

\section{R. Bedi}

Chief Dental Officer - England doi: 10.1038/sj.bdj.4812373

\section{Missed diagnosis}

Sir, although there is implied criticism of the denture technician in the recent paper on an undiagnosed case of malignancy (BDJ 2005,198:341) the authors also make it clear that dental practitioners are sometimes culpable. Indeed, the dental profession should consider why general medical practitioners have been shown to be better at diagnosis and prompt referral than their dental colleagues - surely an embarrassing finding at the very least!

I remember a similar case being referred to me a few years ago by a suitably embarrassed general dental practitioner who admitted that he had completely missed a palatal malignancy in a similar clinical situation when the patient presented with ill-fitting dentures. It was left to the astute technician on this occasion to return the plaster model with the comment that the 'blow hole' looked a little too large to fill in, and that in his opinion it could even be a tumour! Stones and glass houses come to mind!

C. Gardener

By email

doi: $10.1038 /$ sj.bdj.4812374 